\title{
Risk of vascular events in patients with polymyalgia rheumatica
}

\author{
Adam T. Hancock MBChB MPhil, Christian D. Mallen BMBS PhD, Sara Muller PhD, John Belcher PhD, \\ Edward Roddy BMBS MD, Toby Helliwell MBChB MMedSci, Samantha L. Hider BMBS PhD
}

\begin{abstract}
- ABSTRACT
Background: Polymyalgia rheumatica is one of the most common inflammatory rheumatologic conditions in older adults. Other inflammatory rheumatologic disorders are associated with an excess risk of vascular disease. We investigated whether polymyalgia rheumatica is associated with an increased risk of vascular events.

Methods: We used the General Practice Research Database to identify patients with a diagnosis of incident polymyalgia rheumatica between Jan. 1, 1987, and Dec. 31, 1999. Patients were matched by age, sex and practice with up to 5 patients without polymyalgia rheumatica. Patients were followed until their first vascular event (cardiovascular, cerebrovascular, peripheral vascular) or the end of available records (May 2011). All participants were free of vascular disease before the diagnosis of polymyalgia rheumatica (or matched date). We used Cox regression models to compare time to first vascular event in patients with and without polymyalgia rheumatica.
\end{abstract}

Results: A total of 3249 patients with polymyalgia rheumatica and 12735 patients without were included in the final sample. Over a median follow-up period of 7.8 (interquartile range 3.3-12.4) years, the rate of vascular events was higher among patients with polymyalgia rheumatica than among those without (36.1 v. 12.2 per 1000 person-years; adjusted hazard ratio $2.6,95 \%$ confidence interval 2.4-2.9). The increased risk of a vascular event was similar for each vascular disease end point. The magnitude of risk was higher in early disease and in patients younger than 60 years at diagnosis.

Interpretation: Patients with polymyalgia rheumatica have an increased risk of vascular events. This risk is greatest in the youngest age groups. As with other forms of inflammatory arthritis, patients with polymyalgia rheumatica should have their vascular risk factors identified and actively managed to reduce this excess risk.
Competing interests: None declared.

This article has been peer reviewed.

Correspondence to: Christian D. Mallen, c.d.mallen@keele.ac.uk

CMAJ 2014. DOI: $10.1503 /$ cmaj.140266
I nflammatory rheumatologic disorders such as rheumatoid arthritis, ${ }^{1,2}$ systemic lupus erythematosus, ${ }^{2,3}$ gout, ${ }^{4}$ psoriatic arthritis ${ }^{2,5}$ and ankylosing spondylitis ${ }^{2,6}$ are associated with an increased risk of vascular disease, especially cardiovascular disease, leading to substantial morbidity and premature death. ${ }^{2-6}$ Recognition of this excess vascular risk has led to management guidelines advocating screening for and management of vascular risk factors. ${ }^{7-9}$

Polymyalgia rheumatica is one of the most common inflammatory rheumatologic conditions in older adults, ${ }^{10}$ with a lifetime risk of $2.4 \%$ for women and $1.7 \%$ for men. ${ }^{11}$ To date, evidence regarding the risk of vascular disease in patients with polymyalgia rheumatica is unclear. There are a number of biologically plausible mechanisms between polymyalgia rheumatica and vascular disease. These include the inflammatory burden of the disease, ${ }^{12,13}$ the association of the disease with giant cell arteritis (causing an inflammatory vasculopathy, which may lead to subclinical arteritis, stenosis or aneurysms), ${ }^{14}$ and the adverse effects of long-term corticosteroid treatment (e.g., diabetes, hypertension and dyslipidemia). ${ }^{15,16}$ Paradoxically, however, use of corticosteroids in patients with polymyalgia rheumatica may actually decrease vascular risk by controlling inflammation. ${ }^{17} \mathrm{~A}$ recent systematic review concluded that although some evidence exists to support an association between vascular disease and polymyalgia rheumatica, ${ }^{18}$ the existing literature presents conflicting results, with some studies reporting an excess risk of vascular disease $\mathrm{e}^{19,20}$ and vascular death,,$^{21,22}$ and others reporting no association. ${ }^{23-26}$ Most current studies are limited by poor methodologic quality and small samples, and are based on secondary care cohorts, who may have more severe disease, yet most patients with polymyalgia rheumatica receive treatment exclusively in primary care. ${ }^{27}$

The General Practice Research Database (GPRD), based in the United Kingdom, is a large electronic system for primary care records. It has 
been used as a data source for previous studies, ${ }^{28}$ including studies on the association of inflammatory conditions with vascular disease ${ }^{29}$ and on the epidemiology of polymyalgia rheumatica in the UK. ${ }^{30}$ The aim of the current study was to examine the association between polymyalgia rheumatica and vascular disease in a primary care population.

\section{Methods}

\section{The General Practice Research Database}

The GPRD consists of the electronic medical records of patients registered with contributing general practices in England and Wales. More than $95 \%$ of people in the UK are registered with a general practice, with general practitioners acting as "gatekeepers" for many health-related services. The GPRD draws on the records of all patients registered with more than 500 practices; these records represent $6 \%$ of the population of England and Wales. ${ }^{28,31}$ Practices contributing to the GPRD are broadly representative of practices in England and Wales in terms of geographical distribution, patient list size, and the age and sex distribution of patients. The data routinely recorded in the GPRD include demographics, prescription details, clinical events, preventive care, specialist referrals, and hospital admissions and their major outcomes. ${ }^{28}$ To be included in the database, contributing practices must meet strict criteria for data quality ${ }^{31}$ and be declared to have data "up to standard" for research purposes. A review of all validation studies found that medical data in the GPRD were generally of high quality, ${ }^{31}$ with better diagnostic coding for chronic than acute conditions. ${ }^{28}$

\section{Study population}

All patients with a diagnosis of incident polymyalgia rheumatica recorded in the GPRD between Jan. 1, 1987, and Dec. 31, 1999, were identified. Patients were identified by the N-20 Read code (i.e., a coded thesaurus of clinical codes, based on International Classification of Diseases, 9th Revision [Clinical Modification] codes used in general practice in the UK) and individually matched with up to 5 patients without polymyalgia rheumatica, matched for birth year, sex and practice. For patients with polymyalgia rheumatica, the index date was the date of the first Read code for polymyalgia rheumatica. For patients without polymyalgia rheumatica, the index date was the corresponding, matched date. Patients with polymyalgia rheumatica and their matched counterparts were eligible for inclusion if aged 50 years or older at their index date with at least 2 years of "up-to-standard" records available before this date, and no record of vascular events before this date. Matching and data extraction were carried out by GPRD staff, according to their usual procedures.

To be confident in the definition of polymyalgia rheumatica, we applied a method previously used in GPRD research related to polymyalgia rheumatica. ${ }^{30}$ Patients with polymyalgia rheumatica who were registered with the practice for 6 months or longer after the index date were included only if they had at least 2 prescriptions for oral corticosteroids within that period. Patients who ceased to be registered with the practice within 6 months of the index date were included if they had 1 or more prescriptions for oral corticosteroids between the index date and the end of their registration. Patients with a Read code diagnosis of polymyalgia rheumatica who did not fulfill the criterion for steroid prescription were excluded from further analyses, as were their matched counterparts. Polymyalgia rheumatica may mimic other rheumatologic disorders, such as inflammatory arthritis, ${ }^{32}$ and so all patients who received a Read code for an alternative inflammatory rheumatologic diagnosis within 6 months were excluded from the analysis, together with their matched controls.

Participants were followed from their index date to the date of their first vascular event, death, transfer out of the GPRD practice, or until the end of the data excerpt (May 2011), whichever was the earliest.

\section{Outcome measures}

The primary outcome was time to first vascular event. Vascular outcomes were grouped into cardiovascular (e.g., myocardial infarction and angina), cerebrovascular (e.g., ischemic and hemorrhagic stroke, and transient ischemic attack) and peripheral vascular events (e.g., intermittent claudication and ischemia). A list of the Read codes included is available from the authors.

\section{Potential confounders}

Participants' electronic medical records were searched to identify known vascular risk factors (i.e., hypertension, hyperlipidemia, diabetes, ever having smoked) from before the index date. Smoking was defined according to the information provided directly by the GPRD, as ever or never having smoked. We used Read codes to identify participants with a diagnosis of giant cell arteritis either before or after the diagnosis of polymyalgia rheumatica.

\section{Statistical analysis}

Descriptive statistics (means and standard deviations, medians and interquartile ranges) were used as appropriate to describe the sample. We 
used Cox proportional hazard models to ascertain the association between polymyalgia rheumatica and all vascular outcomes over the entire followup period, and at 6 months and 1, 2, 5 and 10 years after the index date. The association of polymyalgia rheumatica with any cardiovascular, cerebrovascular or peripheral vascular events was investigated using similar models. We investigated the association with all vascular events over the entire follow-up period in age- and sexspecific groups. Models were adjusted for age and sex, and for the presence of known traditional vascular risk factors and giant cell arteritis.

We used robust standard errors to correct estimated standard errors for the matched design. ${ }^{33}$ We tested the proportional hazards assumption in all models using graphical methods and Schoenfeld residuals. If models were found to violate the proportional hazards assumption, we refitted models assuming separate baseline hazards for the covariate(s) found to be causing the violation.

We conducted a sensitivity analysis over the entire follow-up period, using all vascular events as the outcome. To account for coexisting giant cell arteritis (because these patients would be expected to receive substantially higher doses of steroids than those with polymyalgia rheumatica alone, and would also be more likely to receive treatment through secondary care), we excluded all patients with a diagnosis of giant cell arteritis, along with their matched groups.

To assess the risk of surveillance bias resulting in less-severe vascular events being diagnosed in those with polymyalgia rheumatica, we examined specific cardiovascular end points (i.e., myocardial infarction, any stroke, ischemic stroke, hemorrhagic stroke, transient ischemic attack) that would require emergency treatment. We also assessed the association with angina, as a less specific diagnosis.

All analyses were performed using Stata 12.1 (StataCorp), and all point estimates were calculated with associated $95 \%$ confidence intervals (CIs).

\section{Ethics approval}

This study received approval from the Independent Scientific Advisory Committee for Medicines and Healthcare Products Regulatory Agency database research (protocol no. 10_109AR).

\section{Results}

We identified 3925 patients with polymyalgia rheumatica and no history of vascular events. The diagnosis of polymyalgia rheumatica could be validated via steroid prescription in 3318 patients, who were matched with a total of 13016 patients without polymyalgia rheumatica
(Appendix 1, available at www.cmaj.ca/lookup/ suppl/doi:10.1503/cmaj.140266/-/DC1). Sixteen patients had a vascular event or were censored on their index date (or the index date of their matched counterpart with polymyalgia rheumatica) and so were excluded from further analyses; 66 patients received an alternative rheumatologic diagnosis (97\% with inflammatory arthritis) and therefore they and their matched controls were excluded. The final sample consisted of 3249 patients with polymyalgia rheumatica and 12735 patients without.

As expected from the matched design, the mean age of patients and proportion of women in both groups were similar (Table 1). The ratio of men to women was 1:2.65. Patients with polymyalgia rheumatica were more likely to have a diagnosis of hypertension, hyperlipidemia or diabetes and to have ever smoked. Smoking status was missing for about 13\% $(n=2090)$ of the sample. Patients with polymyalgia rheumatica were more likely to have their smoking status recorded, with 236 of 3249 (7.3\%) having a missing smoking status compared with 1854 of 12735 (14\%) of controls. These patients were excluded from the adjusted analyses. The median follow-up time for patients with polymyalgia rheumatica was 7.8 (interquartile range [IQR] 3.3-12.4) years, which was significantly longer than the median follow-up time for those without the condition (7.4 [IQR 3.3-12.0]; $p=0.005)$.

Patients with polymyalgia rheumatica were more likely to have a vascular event during the follow-up period than were patients without (hazard ratio [HR] 2.9, 95\% CI 2.6-3.2) (Figure 1). This association remained after adjust-

Table 1: Characteristics of patients with and without a diagnosis of polymyalgia rheumatica

\begin{tabular}{|c|c|c|}
\hline \multirow[b]{2}{*}{ Characteristic } & \multicolumn{2}{|c|}{ Group; no. $(\%)^{*}$} \\
\hline & $\begin{array}{c}\text { PMR } \\
n=3249\end{array}$ & $\begin{array}{c}\text { No PMR } \\
n=12735\end{array}$ \\
\hline Age at index date, $y r$, mean $\pm S D$ & $72.3 \pm 8.9$ & $72.0 \pm 9.1$ \\
\hline Female sex & $2356(72.6)$ & $9245(72.5)$ \\
\hline Smoking status (ever smoked)†‡ & $1308(43.4)$ & 4496 (41.3) \\
\hline Hypertension $\ddagger$ & $1611(51.1)$ & $5241(41.2)$ \\
\hline Diabetesł & $438(13.5)$ & $1266(9.9)$ \\
\hline Hyperlipidemiał & $521(16.0)$ & $1431(11.4)$ \\
\hline Giant cell arteritisł & $248 \quad(7.6)$ & $67(0.5)$ \\
\hline Follow-up time, yr, median (IQR) & $7.8(3.3-12.4)$ & $7.4(3.3-12.0)$ \\
\hline \multicolumn{3}{|c|}{$\begin{array}{l}\text { Note: IQR = interquartile range, PMR = polymyalgia rheumatica, SD = standard deviation. } \\
\text { *Unless stated otherwise. } \\
\text { tContains missing data where smoking status was not recorded in General Practice Research } \\
\text { Database data set ( } 13 \% \text { missing overall). } \\
\text { fRecorded at any time before index date. }\end{array}$} \\
\hline
\end{tabular}


ment for age, sex and known vascular risk factors (HR 2.6, 95\% CI 2.4-2.9) (Table 2). The association was strongest in the first 6 months after the index date and remained significant throughout the follow-up period.

There were similar, significant associations between polymyalgia rheumatica and cerebrovascular (HR 2.6, 95\% CI 2.3-3.0), cardiovascu$\operatorname{lar}($ HR 3.0, 95\% CI 2.7-3.3) and peripheral vascular (HR 3.3, 95\% CI 2.7-4.1) events (Table 3). These associations remained after adjustment for age, sex and vascular risk factors (cerebrovascular: HR 2.3, 95\% CI 2.0-2.6; cardiovascular: HR 2.7, 95\% CI 2.4-3.0; peripheral vascular: HR $2.8,95 \%$ CI 2.2-3.5). For cerebrovascular and cardiovascular events, there were similar trends over time as seen in all events, with a higher risk of such an event during the first 6-12 months after diagnosis of polymyalgia rheumatica and the magnitude of increased risk decreasing over time (data not shown).

The increased risk of a vascular event in those with PMR was similar in men and women (Table 4). However, this association varied across age groups, with patients aged 50-59 years having a more than fivefold increased risk of a vascular event compared with a threefold increased risk among patients aged 80 years and older.

\section{Sensitivity analysis}

After exclusion of the 326 patients with a diagnosis of giant cell arteritis and the remainder of their matched groups $(n=1285)$, the association remained (HR 2.7, 95\% CI 2.4-3.0).

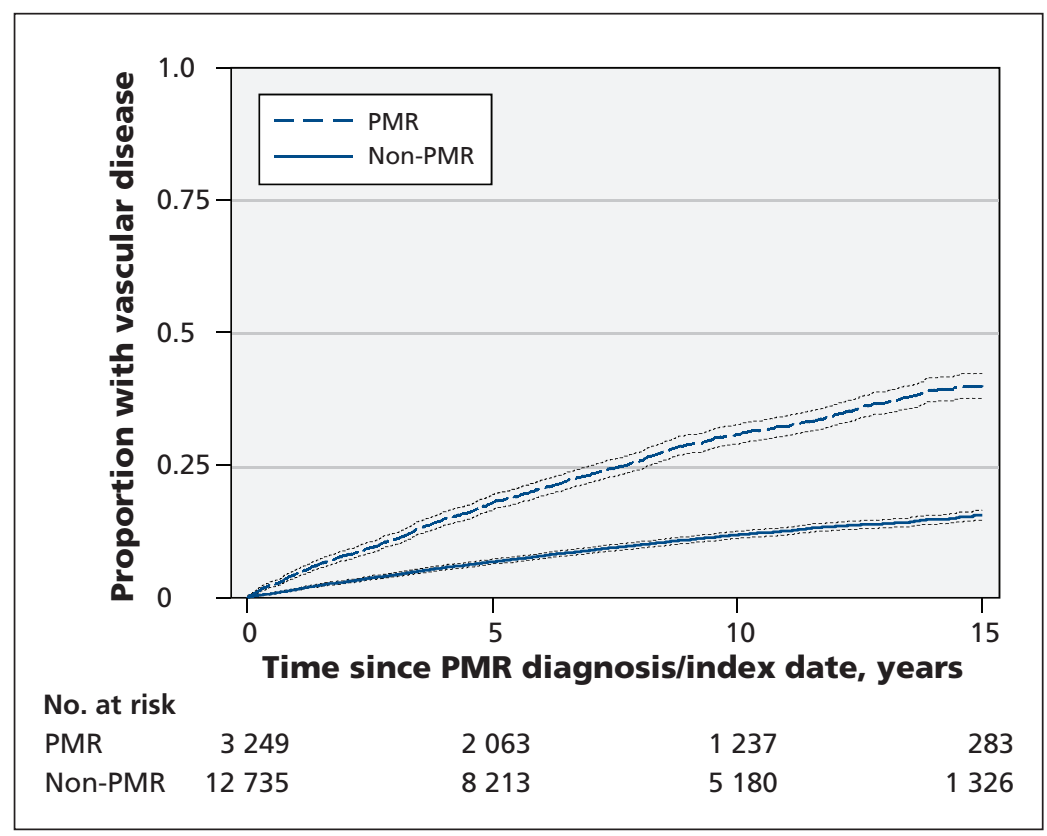

Figure 1: Kaplan-Meier curves for time to first vascular event after the index date among patients with and without a diagnosis of polymyalgia rheumatica (PMR). Dotted lines $=95 \%$ confidence intervals.
When considering only specific vascular end points (i.e., any stroke, hemorrhagic stroke, ischemic stroke, transient ischemic attack, myocardial infarction, angina), the same pattern of association with polymyalgia rheumatica was seen (data not shown). However, its strength was attenuated somewhat, and it was not significant for hemorrhagic stroke where the number of events was small $(n=36)$.

\section{Interpretation}

Our results showed that patients with polymyalgia rheumatica had an increased risk of all types of vascular events, even after traditional risk factors for vascular disease were controlled for. This excess risk was present soon after diagnosis, was present in both men and women, and was largest in younger $(<60 \mathrm{yr})$ patients.

A recent systematic review of polymyalgia rheumatica and vascular disease found conflicting results,${ }^{18}$ with some studies reporting a positive association $^{19,20}$ and others no association. ${ }^{23-25}$ Our study provides robust evidence that polymyalgia rheumatica, in common with other rheumatologic disorders such as rheumatoid arthritis and systemic lupus erythematosus, is associated with an increased vascular risk. In contrast with rheumatoid arthritis and systemic lupus erythematosus (where the greatest cardiovascular risk is in established disease), ${ }^{1}$ in our study cohort the excess risk was seen early in the disease and was present throughout the follow-up period. This early excess risk provides insight into potential mechanisms and supports the link between inflammation and vascular disease, ${ }^{12,13}$ given that the inflammatory burden in polymyalgia rheumatica (measured by erythrocyte sedimentation rate and C-reactive protein level) is highest in early disease. Other studies suggest that inflammation may lead to plaque instability ${ }^{34}$ and, hence, vascular events. Further support for the inflammatory hypothesis comes from a systematic review showing that patients with rheumatoid arthritis who are given methotrexate have a lower risk of cardiovascular disease, probably via better control of inflammation. ${ }^{35}$ Alternatively, the excess risk in polymyalgia rheumatica may be mediated by corticosteroids, via adverse effects on blood pressure and lipids. Study results suggest that prednisolone is associated with increased cardiovascular events at doses higher than $7.5 \mathrm{mg} / \mathrm{d}$, ${ }^{15}$ although other studies of steroid use in polymyalgia rheumatica ${ }^{36}$ and rheumatoid arthritis ${ }^{37}$ did not find an association between steroid dose and vascular risk, suggesting there may be a trade-off between adverse events of steroids on blood pressure and lipids and their efficacy in controlling inflammation. 


\section{Strengths and limitations}

Strengths of our study include the GPRD data set, which is large and well validated. ${ }^{28,31}$ Also, patients were matched by age, sex and practice, which reduces the risk of confounding by sociodemographic and geographic factors.

Our study also has several limitations. As with all database studies, our study is subject to

Table 2: Association between diagnosis of polymyalgia rheumatica and all first vascular events, by follow-up period

\begin{tabular}{|c|c|c|c|c|c|}
\hline \multirow{2}{*}{$\begin{array}{l}\text { Follow-up } \\
\text { period }\end{array}$} & \multirow[b]{2}{*}{ No. } & \multicolumn{2}{|c|}{$\begin{array}{l}\text { All vascular events, rate per } \\
1000 \text { person-years }(95 \% \mathrm{Cl})\end{array}$} & \multicolumn{2}{|c|}{ Hazard ratio $(95 \% \mathrm{Cl})$} \\
\hline & & PMR & No PMR & Unadjusted & Adjusted* \\
\hline $6 \mathrm{mo}$ & 168 & $47.6(38.8-60.7)$ & $14.6(11.9-17.9)$ & $3.3(2.5-4.5)$ & $3.0(2.2-4.2)$ \\
\hline $1 \mathrm{yr}$ & 326 & $45.5(38.6-53.7)$ & $15.2(13.2-17.6)$ & $3.0(2.4-3.7)$ & $2.7(2.1-3.4)$ \\
\hline $2 \mathrm{yr}$ & 522 & $41.2(36.3-46.7)$ & $14.7(13.2-16.4)$ & $2.8(2.4-3.3)$ & $2.4(2.0-2.8)$ \\
\hline $5 \mathrm{yr}$ & 1247 & $39.6(36.3-43.1)$ & $14.1(13.2-15.2)$ & $2.8(2.5-3.1)$ & $2.4(2.1-2.7)$ \\
\hline $10 \mathrm{yr}$ & 1892 & 37.5 (35.0-40.2) & $12.9(12.2-13.8)$ & $2.9(2.6-3.2)$ & $2.5(2.3-2.8)$ \\
\hline $\begin{array}{l}\text { All follow-up } \\
\text { periods }\end{array}$ & 2174 & 36.1 (33.8-38.5) & $12.2(11.6-12.9)$ & $2.9(2.6-3.2)$ & $2.6(2.4-2.9)$ \\
\hline
\end{tabular}

Table 3: Association between diagnosis of polymyalgia rheumatica and first occurrence of each type of vascular event

\begin{tabular}{|c|c|c|c|c|c|}
\hline \multirow{2}{*}{$\begin{array}{l}\text { Type of vascular } \\
\text { event }\end{array}$} & \multirow[b]{2}{*}{ No. } & \multicolumn{2}{|c|}{$\begin{array}{c}\text { Specific vascular events, rate per } \\
1000 \text { person-years }(95 \% \mathrm{Cl})\end{array}$} & \multicolumn{2}{|c|}{ Hazard ratio $(95 \% \mathrm{Cl})$} \\
\hline & & PMR & No PMR & Unadjusted & Adjusted* \\
\hline Cerebrovascular & 1067 & $15.6(14.2-17.2)$ & $5.9(5.5-6.4)$ & $2.6(2.3-3.0)$ & $2.3(2.0-2.6) \dagger$ \\
\hline Cardiovascular & 1134 & $18.1(16.6-19.8)$ & $6.1(5.6-6.6)$ & $3.0(2.7-3.3)$ & $2.7(2.4-3.0)$ \\
\hline Peripheral & 335 & $5.5(4.7-6.4)$ & $1.6(1.4-1.9)$ & $3.3(2.7-4.1)$ & $2.8(2.2-3.5)$ \\
\hline
\end{tabular}

Table 4: Association between diagnosis of polymyalgia rheumatica and all vascular events, by sex and age

\begin{tabular}{|c|c|c|c|c|}
\hline \multirow[b]{2}{*}{ Characteristic } & \multicolumn{2}{|c|}{$\begin{array}{l}\text { All vascular events, rate per } \\
1000 \text { person-years }(95 \% \mathrm{Cl})\end{array}$} & \multicolumn{2}{|c|}{ Hazard ratio $(95 \% \mathrm{Cl})$} \\
\hline & PMR & No PMR & Unadjusted & Adjusted* \\
\hline \multicolumn{5}{|l|}{ Sex } \\
\hline Male & 43.7 (38.9-49.3) & $15.7(14.3-17.3)$ & $2.8(2.4-3.2)$ & $2.5(2.1-2.9)$ \\
\hline Female & $33.5(30.9-36.2)$ & $11.0(10.3-11.8)$ & $3.1(2.7-3.3)$ & $2.7(2.4-2.9) \dagger$ \\
\hline \multicolumn{5}{|l|}{ Age, yr } \\
\hline $50-59$ & $19.5(15.1-25.0)$ & $3.5(2.6-4.6)$ & $5.6(3.8-8.1)$ & $5.0(3.4-7.4)$ \\
\hline $60-69$ & $27.6(24.2-31.5)$ & $8.1 \quad(7.2-9.1)$ & $3.4(2.9-4.1)$ & $2.9(2.4-3.5)$ \\
\hline $70-79$ & $40.1(36.4-44.1)$ & $16.0(14.9-17.3)$ & $2.5(2.2-2.8)$ & $2.3(2.1-2.7)$ \\
\hline$\geq 80$ & $56.9(49.6-64.8)$ & $19.8(17.6-22.3)$ & $2.8(2.4-3.4)$ & $2.6(2.1-3.1)$ \\
\hline
\end{tabular}

Note: $\mathrm{Cl}=$ confidence interval, $\mathrm{PMR}=$ polymyalgia rheumatia.

*Adjusted for age, sex, ever having smoked, and record of hypertension, hyperlipidemia, diabetes or giant cell arteritis. Models stratified by age were adjusted only for sex, and vice versa.

tAssuming separate baseline hazards for those with and without diabetes mellitus. 
the potential for misclassification owing to reliance on accurate event coding. However, by considering vascular outcomes likely to result in hospital admission (e.g., myocardial infarction, stroke), the risk of this (which would be similar in both groups) is reduced. In addition, a previous systematic review of validity of diagnoses within the GPRD suggested the validity of cardiovascular disease coding is high, at over $85 \% .{ }^{28,31}$ There remains, however, the possibility of surveillance bias. Patients with newly diagnosed polymyalgia rheumatica have been shown to consult with physicians more frequently, ${ }^{19}$ and general practitioners may be more vigilant to the development of risk factors such as hypertension or diabetes in patients receiving corticosteroids. Ensuring diagnostic accuracy for polymyalgia rheumatica is difficult. Polymyalgia rheumatica is a clinical diagnosis, and a single diagnostic test does not exist. In the UK, guidelines from the British Society for Rheumatology ${ }^{37}$ encourage a stepped diagnostic approach and emphasize important diagnostic features. Although we were unable to validate the diagnosis of polymyalgia rheumatica using classification criteria, ${ }^{38}$ to improve diagnostic accuracy we restricted our analysis to patients with polymyalgia rheumatica receiving treatment with steroids. It is possible that some patients with other noninflammatory conditions, such as malignant disease, initially received a diagnosis of polymyalgia rheumatica, although inclusion of these patients is likely to have reduced the strength of any association observed and so should not affect our findings.

\section{Conclusion}

Our findings suggest an increased risk of vascular events in patients with polymyalgia rheumatica, independent of other traditional risk factors for vascular disease. Aggressive management of vascular risk factors should be considered in patients with polymyalgia rheumatica to try to attenuate this excess risk.

Further research is needed to investigate the mechanisms of vascular disease in polymyalgia rheumatica, and specifically to assess the burden of risk conferred by traditional cardiovascular risk factors versus the risk conferred by inflammation or treatment with steroids.

\section{References}

1. Avina-Zubieta JA, Thomas J, Sadatsafavi M, et al. Risk of incident cardiovascular events in patients with rheumatoid arthritis: a meta-analysis of observational studies. Ann Rheum Dis 2012;71:1524-9.

2. Roifman I, Beck PL, Anderson TJ, et al. Chronic inflammatory diseases and cardiovascular risk: a systematic review. Can J Cardiol 2011;27:174-82

3. Bengtsson C, Ohman ML, Nived O, et al. Cardiovascular event in systemic lupus erythematosus in northern Sweden: inci- dence and predictors in a 7-year follow-up study. Lupus 2012;21:452-9.

4. Clarson L, Chandratre P, Hider S, et al. Increased cardiovascular mortality associated with gout: a systematic review and meta-analysis. Eur J Prev Cardiol 2013 Dec. 17. (Epub ahead of print)

5. Atzeni F, Turiel M, Boccassini L, et al. Cardiovascular involvement in psoriatic arthritis. Reumatismo 2011;63:148-54.

6. Mathieu S, Gossec L, Dougados M, et al. Cardiovascular profile in ankylosing spondylitis: a systematic review and metaanalysis. Arthritis Care Res (Hoboken) 2011;63:557-63.

7. Jordan KM, Cameron JS, Snaith M, et al. British Society for Rheumatology and British Health Professionals in Rheumatology guideline for the management of gout. Rheumatology (Oxford) 2007;46:1372-4.

8. Luqmani R, Hennell S, Estrach C, et al. British Society for Rheumatology and British Health Professionals in Rheumatol ogy guideline for the management of rheumatoid arthritis (after the first 2 years). Rheumatology (Oxford) 2009;48:436-9.

9. Peters MJ, Symmons DP, McCarey D, et al. EULAR evidencebased recommendations for cardiovascular risk management in patients with rheumatoid arthritis and other forms of inflammatory arthritis. Ann Rheum Dis 2010;69:325-31.

10. Michet CJ, Matteson EL. Polymyalgia rheumatica. BMJ 2008;336:765-9.

11. Crowson CS, Matteson EL, Myasoedova E, et al. The lifetime risk of adult-onset rheumatoid arthritis and other inflammatory autoimmune rheumatic diseases. Arthritis Rheum 2011; 63:633-9.

12. Hansson GK. Inflammation, atherosclerosis, and coronary artery disease. N Engl J Med 2005;352:1685-95.

13. Genest J. C-reactive protein: risk factor, biomarker and/or therapeutic target? Can J Cardiol 2010;26(Suppl A):41A-4A.

14. Mackie SL, Hensor EM, Morgan AW, et al. Should I send my patient with previous giant cell arteritis for imaging of the thoracic aorta? A systematic literature review and meta-analysis. Ann Rheum Dis 2014;73:143-8.

15. Wei L, MacDonald TM, Walker BR. Taking glucocorticoids by prescription is associated with subsequent cardiovascular disease. Ann Intern Med 2004;141:764-70.

16. Gabriel SE, Sunku J, Salvarani C, et al. Adverse outcomes of antiinflammatory therapy among patients with polymyalgia rheumatica. Arthritis Rheum 1997;40:1873-8.

17. Maradit Kremers H, Reinalda MS, Crowson CS, et al. Glucocorticoids and cardiovascular and cerebrovascular events in polymyalgia rheumatica. Arthritis Rheum 2007;57:279-86.

18. Hancock AT, Mallen CD, Belcher J, et al. The association between polymyalgia rheumatica and vascular disease; a systematic review. Arthritis Care Res (Hoboken) 2012;64:1301-5.

19. Kremers HM, Reinalda MS, Crowson CS, et al. Direct medical costs of polymyalgia rheumatica. Arthritis Rheum 2005; 53:578-84.

20. Warrington KJ, Jarpa EP, Crowson CS, et al. Increased risk of peripheral arterial disease in polymyalgia rheumatica: a population-based cohort study. Arthritis Res Ther 2009;11:R50.

21. Schaufelberger C, Bengtsson BA, Andersson R. Epidemiology and mortality in 220 patients with polymyalgia rheumatica. $\mathrm{Br}$ J Rheumatol 1995;34:261-4

22. Uddhammar A, Eriksson AL, Nyström L, et al. Increased mortality due to cardiovascular disease in patients with giant cell arteritis in northern Sweden. J Rheumatol 2002;29:737-42.

23. Andersson R, Malmvall BE, Bengtsson BA. Long-term survival in giant cell arteritis including temporal arteritis and polymyalgia rheumatica. A follow-up study of 90 patients treated with corticosteroids. Acta Med Scand 1986;220:361-4.

24. Bengtsson BA, Malmvall BE. Prognosis of giant cell arteritis including temporal arteritis and polymyalgia rheumatica. A follow-up study on ninety patients treated with corticosteroids. Acta Med Scand 1981;209:337-45.

25. Myklebust G, Wilsgaard T, Jacobsen BK, et al. Causes of death in polymyalgia rheumatica. A prospective longitudinal study of 315 cases and matched population controls. Scand J Rheumatol 2003;32:38-41.

26. Pfadenhauer K, Esser M, Berger K. Vertebrobasilar ischemia and structural abnormalities of the vertebral arteries in active temporal arteritis and polymyalgia rheumatic - an ultrasonographic case-control study. J Rheumatol 2005;32:2356-60.

27. Barraclough K, Liddell WG, du Toit J, et al. Polymyalgia rheumatica in primary care: a cohort study of the diagnostic criteria and outcome. Fam Pract 2008;25:328-33.

28. Khan NF, Harrison SE, Rose PW. Validity of diagnostic coding within the General Practice Research Database: a systematic review. Br J Gen Pract 2010;60:e128-36.

29. Mikuls TR, Farrar JT, Bilker WB, et al. Gout epidemiology: 
results from the UK General Practice Research Database, 1990-1999. Ann Rheum Dis 2005;64:267-72.

30. Smeeth L, Cook C, Hall AJ. Incidence of diagnosed polymyalgia rheumatica and temporal arteritis in the United Kingdom, 1990-2001. Ann Rheum Dis 2006;65:1093-8.

31. Herrett E, Thomas SL, Schoonen WM, et al. Validation and validity of diagnoses in the General Practice Research Database: a systematic review. Br J Clin Pharmacol 2010;69:4-14.

32. Gonzalez-Gay MA, Garcia-Porrua C, Salvarani C, et al. The spectrum of conditions mimicking polymyalgia rheumatica in Northwestern Spain. J Rheumatol 2000;27:2179-84.

33. White H. A heteroskedasticity-consistent covariance matrix estimator and a direct test for heteroskedasticity. Econometrica 1980;48:817-38.

34. Shah PK. Inflammation and plaque vulnerability. Cardiovasc Drugs Ther 2009;23:31-40.

35. Micha R, Imamura F, Wyler von Ballmoos M, et al. Systematic review and meta-analysis of methotrexate use and risk of cardiovascular disease. Am J Cardiol 2011;108:1362-70.

36. Svensson B, Hafström I. Effects on joint destruction and remission, bone turnover and lack of influence on atherogenesis: a review of the BARFOT low-dose prednisolone studies on patients with early RA. Clin Exp Rheumatol 2011;29(Suppl 68): S63-7.

37. Dasgupta B, Borg FA, Hassan N, et al.; BSR and BHPR Standards, Guidelines and Audit Working Group. BSR and BHPR guidelines for the management of polymyalgia rheumatica. Rheumatology (Oxford) 2010;49:186-90.

38. Dasgupta B, Cimmino MA, Maradit-Kremers H, et al. 2012 provisional classification criteria for polymyalgia rheumatica: a European League Against Rheumatism/American College of Rheumatology collaborative initiative. Ann Rheum Dis 2012;71:484-92.
Affiliation: Arthritis Research UK Primary Care Centre, Keele University, Keele, Staffordshire, UK

Contributors: Christian Mallen, Samantha Hider, Edward Roddy and Toby Helliwell conceived the idea for the study. Adam Hancock, Sara Muller and John Belcher conducted the analysis. All of the authors interpreted the findings. Adam Hancock drafted the manuscript, which all of the authors revised. All of the authors approved the final version submitted for publication.

Funding: Adam Hancock received funding from The Jean Shanks Foundation. Christian Mallen is supported by a Clinical Scientist Award from Arthritis Research UK (no. 19634). Sara Muller and Toby Helliwell receive funding from the National Institute for Health Research School for Primary Care Research.

Disclaimer: This study is based in part on data from the Full Feature General Practice Research Database obtained under license from the Medicines and Healthcare Products Regulatory Agency. However, the interpretation and conclusions contained in this study are those of the authors alone. This article presents independent research funded by the National Institute for Health Research. The views expressed are those of the author(s) and not necessarily those of the National Health Service, the National Institute for Health Research or the Department of Health.

Acknowledgements: The authors thank Elaine Hay, Peter Croft, Danielle van der Windt, Kate Dunn and Lorna Clarson for their comments on drafts of the manuscript. 